\title{
The effect of urea exposure on isoaspartyl content and protein L-isoaspartate methyltransferase activity in Drosophila melanogaster
}

\author{
Cynthia L. David ${ }^{\mathrm{a}, 1}$, Valerie A. Pierce ${ }^{\mathrm{b}, 2}$, Dana W. Aswad ${ }^{\mathrm{a}, *}$, Allen G. Gibbs ${ }^{\mathrm{b}, 3}$ \\ ${ }^{a}$ Department of Molecular Biology and Biochemistry, University of California, Irvine, Irvine, CA 92697-3900, USA \\ ${ }^{\mathrm{b}}$ Department of Ecology and Evolutionary Biology, University of California, Irvine, Irvine, CA 92697-2525, USA
}

Received 24 May 1999; received in revised form 12 August 1999; accepted 16 August 1999

\begin{abstract}
Urea is a protein unfolding agent that can accumulate to locally high concentrations in tissues of many organisms. We used Drosophila melanogaster to test the hypothesis that urea loading would promote formation of isoaspartate ( $\beta$-carboxyl-linked aspartate), a common form of protein damage that occurs most readily in unstructured polypeptides and flexible regions of folded proteins. Ten populations of flies were tested; five control populations of urea-sensitive flies and five previously selected urea-tolerant populations. We measured the effects of urea consumption on levels of both isoaspartate and protein L-isoaspartate methyltransferase (PIMT), an enzyme believed to function in the repair or removal of isoaspartyl proteins. For both sets of populations, urea feeding for 6 days increased isoaspartyl levels by approximately $60 \%$, supporting the idea that disruption of protein secondary and tertiary structures can accelerate the formation of isoaspartate in vivo. Urea feeding tended to increase PIMT activity in both control and urea-tolerant populations. There were no significant differences in PIMT activities or isoaspartyl levels between the control and urea-tolerant flies raised on normal or urea food. The latter findings indicate that urea tolerance evolved in the selected populations without any significant change in PIMT expression or activity. (C) 1999 Elsevier Science Inc. All rights reserved.
\end{abstract}

Keywords: Adaptation; Drosophila; Evolution; Isoaspartate; Laboratory selection; Methyltransferase; Protein damage; Urea

\section{Introduction}

Urea is a cytotoxic compound, which nevertheless accumulates to high levels in mammalian kidneys, the tissues of elasmobranch fishes (rays and sharks), and in other biological systems [23]. Urea destabilizes proteins and nucleic acids, and is therefore commonly used as a denaturant in the laboratory. Organisms which accumulate urea generally also amass other compounds,

Abbreviations: AdoMet, $S$-adenosyl-L-methionine; ANOVA, analyses of variance; $\mathrm{dpm} / \mathrm{pmol}$, disintegrations $\min ^{-1} \mathrm{pmol}^{-1}$; PIMT, protein L-isoaspartate methyltransferase; TCA, trichloroacetic acid.

* Corresponding author. Tel.: + 1-949-824-6866; fax: + 1-949-8248551 .

E-mail address: dwaswad@uci.edu (D.W. Aswad)

${ }^{1}$ Present address: Department of Pediatrics, University of Arizona, Tucson, AZ 85724, USA.

${ }^{2}$ Present address: Department of Biology, College of Staten Island/ CUNY, Staten Island, NY 10314, USA.

${ }^{3}$ Present address: Department of Ecology and Evolutionary Biology, University of Arizona, Tucson, AZ 85721, USA. such as trimethylamine oxide, which stabilize protein structure and counteract urea's harmful effects [23]. Intracellular urea concentrations in these animals can exceed $300 \mathrm{mM}$, levels that are toxic to most cells. Resistance to urea's toxic effects can be achieved in the laboratory by selectively breeding urea-tolerant individuals. Mueller and colleagues subjected populations of the fruit fly, Drosophila melanogaster, to increasing levels of dietary urea for 25 generations [10]. In the larval stages, these populations live in and consume media containing $300 \mathrm{mM}$ urea, which causes nearly complete mortality in unselected D. melanogaster. We are interested in elucidating the biochemical bases responsible for the selected flies' ability to survive in this environment. Recent work by some of us has demonstrated that the selected flies contain less urea than the control flies [18]. It is unknown if the selected flies accomplish this by decreasing uptake of urea, increasing urea excretion, or by some other means. 
Another way to ameliorate urea's toxic effects would be to repair the damage it causes. Larvae adapted to the presence of urea may have increased their resistance to protein damage, or increased their ability to repair damaged proteins. As proteins relax their tertiary structures, they become vulnerable to digestion by proteases, and to nonenzymatic chemical reactions such as oxidation of the sulfur atoms of methionine and cysteine and formation of isoaspartate. Isoaspartate ( $\beta$-carboxyllinked aspartate) is generated within labile sequences by the deamidation of asparagine or isomerization of aspartate. Most organisms, including fruit flies, have an enzyme, protein L-isoaspartate methyltransferase (PIMT) (EC 2.1.1.77), which specifically methylates the carboxyl moiety on L-isoaspartyl groups [9,12,15-17]. This enzyme is believed to function in protein repair, because the methyl ester reaction products are unstable and spontaneously break down, ultimately forming a mixture of aspartate- and isoaspartate-containing proteins in a 1:3 ratio ([2] and references therein). In vitro experiments have shown that recycling through this pathway converts most of the original isoaspartate to aspartate $[8,14]$.

Because urea is a protein denaturant, we hypothesized that larvae fed urea-containing media would contain higher levels of isoaspartate than larvae fed normal media. They might also express PIMT at higher levels in order to repair these proteins, and populations selected for urea tolerance may have higher levels than unselected control populations. To distinguish between phenotypic responses to urea and evolved changes due to selection for urea-tolerant $D$. melanogaster, we compared selected and control populations reared on both urea-containing and normal food. Our results suggest that dietary urea caused increased protein damage, as indicated by isoaspartyl levels, and that PIMT activity was mildly increased under these conditions. However, isoaspartyl and PIMT levels did not differ between urea-selected and control populations, on either food treatment, indicating that selection for urea tolerance did not affect these parameters.

\section{Materials and methods}

\subsection{Materials}

Bovine $\gamma$-globulins were purchased from Sigma. Radiolabeled $\quad S$-adenosyl-[methyl- $\left.{ }^{3} \mathrm{H}\right] \mathrm{L}$-methionine $\left(\left[{ }^{3} \mathrm{H}\right]\right.$ AdoMet) was purchased from New England Nuclear. Unlabeled AdoMet was purchased from Sigma and purified on carboxymethyl cellulose [4] before using it to dilute the $\left[{ }^{3} \mathrm{H}\right]$ AdoMet to the desired specific activity. Recombinant rat PIMT was purified as described [6] and had a specific activity of $15200 \mathrm{U} / \mathrm{mg}$, where $1 \mathrm{U}$ is defined as $1 \mathrm{pmol}$ methyl transferred to bovine $\gamma$-globulins per min at $30^{\circ} \mathrm{C}$.

\subsection{Experimental populations and selection protocol}

The flies were derived from five baseline ('B') populations originally founded by Michael R. Rose [20]. These flies have been reared since 1980 on banana medium (normal food), under a 14-day generation cycle, at $25^{\circ} \mathrm{C}$, with constant illumination. A urea-selected (MX) population was derived from each B population by providing larvae with banana medium containing urea (urea food) [10]. Adults were maintained in population cages with normal food, so that only the larvae were exposed to urea. The initial urea concentration was 200 $\mathrm{mM}$, which was gradually increased to $300 \mathrm{mM}$ over the first 25 generations. At the time of our experiments, the populations had undergone greater than 100 generations of selection. Five control (UU) populations were also derived from the $\mathrm{B}$ flies. These were reared under conditions identical to the MX populations, except that the larvae developed in urea-free medium (normal food).

\subsection{Experimental design and statistical analysis}

To remove parental effects, the populations were raised under identical, nonselective conditions for one generation before the experiment was begun. The experimental generation consisted of four groups, each replicated fivefold: control populations reared on normal and $300 \mathrm{mM}$ urea food, and urea-selected populations reared on normal and $300 \mathrm{mM}$ urea food. Control populations reared on urea food develop through the larval stages, albeit more slowly than on normal food [10], but suffer nearly complete mortality during pupation [21]. All measurements were done on third-instar wandering larvae, the stage just prior to pupation. Two-way analyses of variance (ANOVA) on population means were used to examine the effects of selection treatment and food type and the interaction of these terms on the traits measured. Two statistical tests, Dixon's and Grubb's tests, were used to identify outliers [22]. All data are presented as means of populations $(n=5) \pm 1$ S.D. All analyses were performed using Minitab version 10 or SYSTAT for Windows.

\subsection{Extract preparation}

Each extract was prepared from 40 larvae which had been washed with $400 \mathrm{mM}$ sucrose after collection and stored at $-70^{\circ} \mathrm{C}$. The larvae were homogenized in 300 $\mu 1$ homogenization buffer $(100 \mathrm{mM} \mathrm{Na}$ phosphate $\mathrm{pH}$ 6.8, $2 \mathrm{mM}$ EDTA, $15 \mathrm{mM} \beta$-mercaptoethanol, $100 \mu \mathrm{M}$ phenylmethylsulfonyl fluoride, $0.5 \mu \mathrm{g} / \mathrm{ml}$ leupeptin, 0.7 $\mu \mathrm{g} / \mathrm{ml}$ pepstatin) with 30 strokes in a $1.5-\mathrm{ml}$ microfuge tube with a Kontes glass pestle. Homogenates were centrifuged at $15800 \times g$ for $10 \mathrm{~min}$ at $4^{\circ} \mathrm{C}$. Supernatants were recovered and glycerol was added to a final concentration of $5 \%$. Extracts were stored at $-70^{\circ} \mathrm{C}$. 


\subsection{PIMT assay}

Extract (106 $\mu \mathrm{g}$ protein) was mixed with $20 \mu \mathrm{M}$ $\left[{ }^{3} \mathrm{H}\right]$ AdoMet (14000 disintegrations $\mathrm{min}^{-1} \mathrm{pmol}^{-1}$ (dpm/pmol)), $500 \mu \mathrm{g} \gamma$-globulins in $10 \mathrm{mM} \mathrm{HCl}, 100$ $\mathrm{mM} \mathrm{Na}$ phosphate, $0.5 \mathrm{mM}$ EDTA, $\mathrm{pH} 6.7$ in $1.5-\mathrm{ml}$ microfuge tubes. Final reaction volume was $50 \mu$. Blank reactions to measure endogenous methylation consisted of the same mixture without $\gamma$-globulins added. The reactions were incubated at $30^{\circ} \mathrm{C}$ for 15
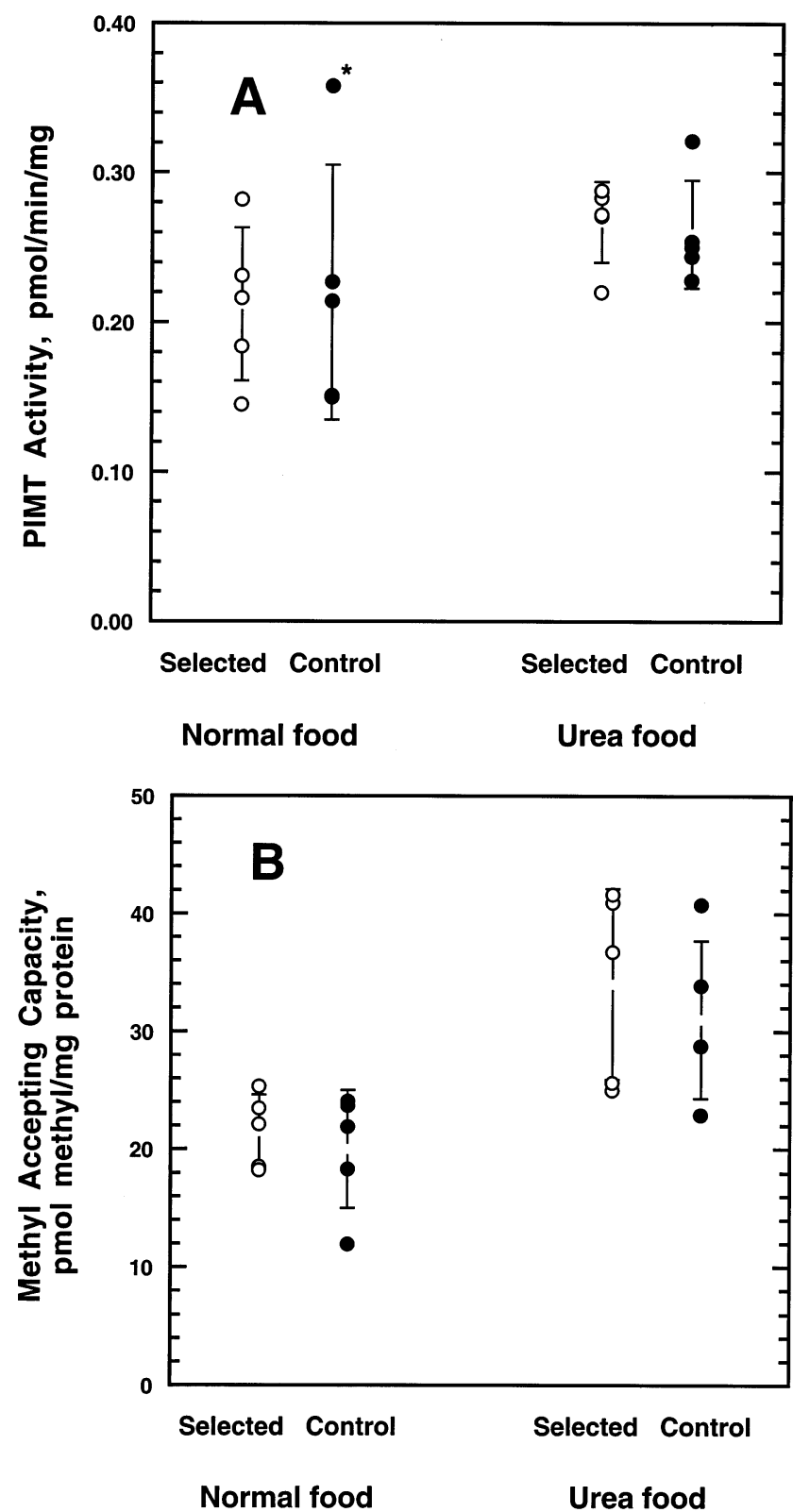

Fig. 1. (A) Variation in PIMT activity and (B) protein isoaspartyl content in selected and in control D. melanogaster populations. Open circles, flies selected for urea tolerance; closed circles, control flies. Enzyme activity and protein methyl accepting capacity were measured as described in Section 2. Each point is the mean of two measurements for a given population, error bars represent S.D. An asterisk indicates a data point that may be an outlier (see Section 3). min. Reactions were stopped with $0.7 \mathrm{ml}$ of $7 \%$ trichloroacetic acid (TCA), vortexed, and placed on ice for $5 \mathrm{~min}$. If the reaction did not include $\gamma$-globulins, 10 $\mu 1$ of a $25 \mathrm{mg} / \mathrm{ml}$ solution of $\gamma$-globulins in $10 \mathrm{mM} \mathrm{HCl}$ was added after the TCA. Tubes were centrifuged at $12000 \times g$ for $30 \mathrm{~s}$, supernatants were aspirated and discarded, and the pellets were washed with $0.7 \mathrm{ml}$ $\mathrm{H}_{2} \mathrm{O}$. Pellets were dissolved in $100 \mu \mathrm{l} 2 \% \mathrm{MeOH}, 0.2 \mathrm{~N}$ $\mathrm{NaOH}$, and $80 \mu \mathrm{l}$ was spotted onto accordion-pleated filter paper lodged in a shell vial top. The top was then placed over a shell vial containing $2.5 \mathrm{ml}$ Liquiscint (National Diagnostics). Vials were heated at $40^{\circ} \mathrm{C}$ for 1 $h$ to allow the hydrolyzed $\left[{ }^{3} \mathrm{H}\right] \mathrm{CH}_{3} \mathrm{OH}$ to diffuse into the cocktail, then the filter papers were removed and radioactivity in the vials was measured by a liquid scintillation counter. The reported enzyme activity is the methylation measured in the presence of $\gamma$-globulins minus the methylation measured in the absence of $\gamma$-globulins.

\subsection{Methyl-accepting capacity}

Reactions consisted of $66.5 \mu \mathrm{g}$ extract proteins, 36 $\mu \mathrm{M}\left[{ }^{3} \mathrm{H}\right]$ AdoMet $(6700 \mathrm{dpm} / \mathrm{pmol}), 1.1 \mu \mathrm{M}$ PIMT, in $62 \mathrm{mM} \mathrm{Na}$ phosphate, $20 \mathrm{mM}$ Na citrate, $2 \mathrm{mM}$ EDTA, pH 6.2. Final reaction volume was $50 \mu$. The reactions were started by the addition of extract proteins. Microfuge tubes $(1.5 \mathrm{ml})$ were incubated at $30^{\circ} \mathrm{C}$ for $15 \mathrm{~min}$. Blank reactions contained homogenization buffer instead of extract protein. Reactions were stopped with $0.7 \mathrm{ml}$ of $7 \%$ TCA, $250 \mu \mathrm{g} \gamma$-globulins were added, and the samples were processed as described above for the PIMT assay.

\subsection{Other methods}

Protein concentrations were measured using the method of Lowry et al. [13] after precipitation in a final concentration of 5\% TCA. Urea concentrations in the larvae were determined spectrophotometrically as described previously [18].

\section{Results}

The effects of urea feeding on PIMT activity and isoaspartyl levels in extracts of D. melanogaster are shown in Fig. 1. PIMT activity was similar in the selected and control populations. Although there was an elevation in enzyme levels for both sets of flies when the flies were fed urea-containing food, the increase was of low statistical significance $(P<0.07)$. One control population on normal food had a PIMT activity $58 \%$ higher than that of the next highest population in the same treatment group (Fig. 1A). Both Dixon's and Grubb's tests rejected the hypothesis that this data 


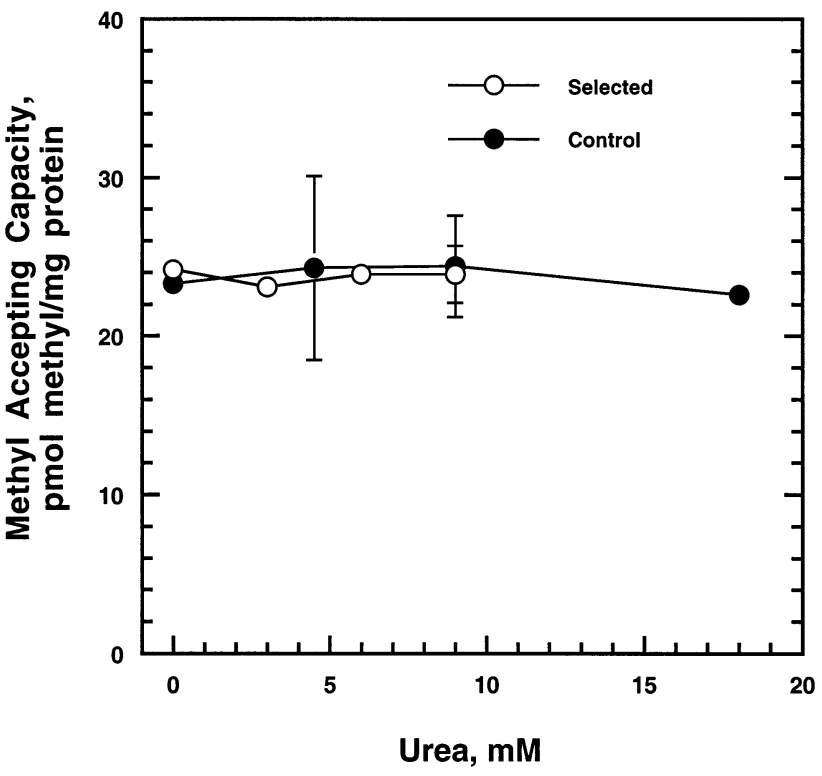

Fig. 2. Exogenous urea does not change the isoaspartyl content of $D$. melanogaster larval extracts. Open circles, flies selected for urea tolerance; closed circles, control flies. Pools were made from selected and control extracts prepared from larvae reared on normal food. Urea was added to the extracts, which were then assayed for methyl accepting capacity as described in Section 2. Each point is the mean of three measurements, error bars represent S.D. Where no error bars appear, the S.D. was less than $4 \%$ of the mean.

point was an outlier at the $P<0.05$ level but accepted it at the $P<0.10$ level. When an ANOVA on PIMT activity was performed without including this data point, PIMT activity was higher in both control and selected populations reared on urea food $(P=0.003)$. These analyses suggest that PIMT activity may be increased when the flies are fed urea food. However, because the effect was not selection-treatment dependent, we conclude that increased expression of PIMT is not one of the mechanisms used by the urea-tolerant flies to survive the urea exposure.

Protein isoaspartyl content, as measured by methylaccepting capacity, was the same for the selected and control flies, $P=0.414$ (Fig. 1B). However, when the flies were fed urea-containing food, the isoaspartyl content of extract proteins rose by $55-58 \%$, and the increase was highly significant $(\mathrm{P}<0.001)$.

We considered the possibility that the increased isoaspartyl levels in urea-fed larvae might be due simply to the presence of urea in the assay mixture, which could partially unfold proteins and expose more sites to methylation by PIMT. To test this possibility, we added $0-18 \mathrm{mM}$ urea to extracts prepared from larvae reared on normal food. (Extracts from urea-fed larvae contained less than $10 \mathrm{mM}$ urea [18].) Extracts were incubated with urea on ice for $1 \mathrm{~h}$, then the methyl-accepting capacity was determined as described in Section 2. We detected no difference in the methyl- accepting capacity of these extracts, regardless of the concentration of urea used (Fig. 2). Therefore, we conclude that the increase seen in protein isoaspartyl levels between flies fed normal food and flies fed urea food was due to isoaspartate forming in the urea-fed flies in vivo, and not in the extracts in vitro.

\section{Discussion}

After greater than 100 generations of selection, the selected $D$. melanogaster populations are able to grow and develop in food containing $300 \mathrm{mM}$ urea. The physiological mechanisms allowing resistance to urea are poorly understood. Larvae from the selected populations cannot exclude urea from their tissues, although they contain lower levels than the controls (79.1 vs $125.6 \mathrm{nmol}$ urea $/ \mathrm{mg}$ larvae) [18]. Urea is generally considered to be a membrane-permeant compound, although specific transport proteins are found in many tissues [11]. There is no evidence that the selected populations accumulate urea-counteracting solutes such as trimethylamine oxide [18]; thus, one would expect proteins to be destabilized in larvae fed urea. Increased protein flexibility results in higher rates of isoaspartate formation in vitro $[1,3,5,7,19]$ and may contribute to the toxic effects of urea.

We found that urea exposure increased in vivo isoaspartate formation in D. melanogaster. Both control and selected larvae had greater than 50\% higher isoaspartyl levels when reared on urea food compared to rearing on normal food. The level of isoaspartate in extracts of the selected flies was the same as that in the control flies, suggesting that selection for urea tolerance has not produced genetic adaptations that reduce this type of protein damage. We also observed a small increase in PIMT activity in larvae reared on urea food. Again, there was no difference in activity between the control and selected larvae, indicating that PIMT levels have not changed in response to urea selection. This absence of an evolved change may explain why we see no reduction in isoaspartyl levels in the selected larvae.

Several possible explanations exist for the lack of evolved differences in isoaspartyl and PIMT levels between the selected and control populations. First, isoaspartate accumulation may not contribute to the death of these larvae, and thus selection has not reduced its levels. Second, there may be insufficient genetic variation for PIMT activity, and thus selection would have no variation on which to act. Third, reducing isoaspartyl levels may indeed be beneficial to ureafed larvae, but increased PIMT levels may have additional, detrimental effects on survival. Thus, counteracting selective forces may result in no net change in PIMT activities. Finally, the PIMT gene could be closely linked to a locus that is even more important for 
urea tolerance. Strong selection on the linked gene may have restricted the evolution of increased PIMT activity. These hypotheses can be tested, by subjecting populations to stronger urea selection, by genetically manipulating PIMT levels, and by using different founding populations, which will contain a different suite of genetic variation.

\section{Acknowledgements}

This work was supported by NIH grant NS17269 to D.W. Aswad, NSF grant IBN-9317471 to A.G. Gibbs, and UCI Multi-Investigator Award to A.G. Gibbs, D.W. Aswad, and L.D. Mueller. We thank Jason Lee for assisting in extract preparation and Kasra Rowshan for protein determinations. We thank Dr Laurence Mueller for providing D. melanogaster and for comments on the manuscript.

\section{References}

[1] Artigues A, Birkett A, Schirch V. Evidence for the in vivo deamidation and isomerization of an asparaginyl residue in cytosolic serine hydroxymethyltransferase. J Biol Chem 1990;265:4853-8.

[2] Brennan TV, Clarke S. Deamidation and isoaspartate formation in model synthetic peptides: the effects of sequence and solution environment. In: Aswad DW, editor. Deamidation and Isoaspartate Formation in Peptides and Proteins. Boca Raton, FL: CRC Press, 1995:65-90.

[3] Chazin WJ, Kossiakof AA. The role of secondary and tertiary structures in intramolecular deamidation of proteins. In: Aswad DW, editor. Deamidation and Isoaspartate Formation in Peptides and Proteins. Boca Raton, FL: CRC Press, 1995:193-206.

[4] Chirpich TP. Ph.D. dissertation. University of California, Berkeley, CA, 1968

[5] Clarke S. Propensity for spontaneous succinimide formation from aspartyl and asparaginyl residues in cellular proteins. Int $\mathbf{J}$ Pept Protein Res 1987;30:808-21.

[6] David CL, Aswad DW. Cloning, expression, and purification of rat brain protein L-isoaspartyl methyltransferase. Protein Expr Purif 1995;6:312-8.

[7] Galletti P, Jardino P, Ingrosso D, Manna C, Zappia V. Enzymatic methyl esterification of a deamidated form of mouse epidermal growth factor. Int J Pept Protein Res 1989;33:397402.

[8] Johnson BA, Murray ED Jr, Clarke S, Glass DB, Aswad DW. Protein carboxyl methyltransferase facilitates conversion of atypical L-isoaspartyl peptides to normal L-aspartyl peptides. J Biol Chem 1987;262:5622-9.

[9] Johnson BA, Ngo SQ, Aswad DW. Widespread phylogenetic distribution of a protein methyltransferase that modifies Lisoaspartyl residues. Biochem Int 1991;24:841-7.

[10] Joshi A, Knight CD, Mueller LD. Genetics of larval urea tolerance in Drosophila melanogaster. Heredity 1996;77:33-9.

[11] Knepper MA, Star RA. The vasopressin-regulated urea transporter in renal inner medullary collecting duct. Am J Physiol 1990;259:F393-401.

[12] Li C, Clarke S. Distribution of an L-isoaspartyl protein methyltransferase in eubacteria. J Bacteriol 1992;174:355-61.

[13] Lowry OH, Rosebrough NJ, Farr AL, Randall RJ. Protein measurement with the Folin phenol reagent. J Biol Chem 1951;193:265-75.

[14] McFadden PN, Clarke S. Conversion of isoaspartyl peptides to normal peptides: Implications for the cellular repair of damaged proteins. Proc Natl Acad Sci USA 1987;84:2595-9.

[15] Mudgett MB, Lowenson JD, Clarke S. Protein repair Lisoaspartyl methyltransferase in plants. Plant Physiol 1997;115:1481-9.

[16] O'Connor CM, Clarke S. Specific recognition of altered polypeptides by widely distributed methyltransferases. Biochem Biophys Res Commun 1985;132:1144-50.

[17] O'Connor MB, Galus A, Hartenstine M, Magee M, Jackson FR, O'Connor CM. Structural organization and developmental expression of the protein isoaspartyl methyltransferase gene from Drosophila melanogaster. Insect Biochem Mol Biol 1997;27:4954.

[18] Pierce VA, Mueller LD, Gibbs AG. Osmoregulation in Drosophila melanogaster selected for urea tolerance. J Exp Biol 1999;202:2349-58.

[19] Potter SM, Henzel WJ, Aswad DW. In vitro aging of calmodulin generates isoaspartate at multiple Asn-Gly and Asp-Gly sites in calcium-binding domains II, III, and IV. Protein Sci 1993;2:1648-63.

[20] Rose MR. Laboratory evolution of postponed senescence in Drosophila melanogaster. Evolution 1984;38:1004-10.

[21] Shiotsugu J, Leroi AM, Yashiro H, Rose MR, Mueller LD. The symmetry of correlated selection responses in adaptive evolution: an experimental study using Drosophila. Evolution 1997;51:16372.

[22] Sokal RR, Rohl FJ. Biometry. San Francisco, CA: W.H. Freeman, 1982.

[23] Somero GN, Yancey PH. Osmolytes and cell-volume regulation: physiological and evolutionary principles. In: Hoffman JF, Jamieson JD, editors. Handbook of Physiology. New York: Oxford University Press, 1997:441-84. 